\title{
CONTROL OF REACTIVE DISTILLATION COLUMNS FOR AMYL ACETATE PRODUCTION USING DILUTE ACETIC ACID
}

\author{
Wan-Jen Hung, I-Kuan Lai, Shih-Bo Hung, Hsiao-Ping Huang, \\ Ming-Jer Lee, and Cheng-Ching $\mathrm{Yu}^{*}$
}

\begin{abstract}
This work explores the feasibility of recovery of acetic acid from aqueous solutions with different acid concentrations. Instead of separating acid from water using azeotropic distillation, acetic acid is converted to acetate via esterification. A range of acetic acid concentrations is explored, varying from $100 \mathrm{wt} \%$, to $75 \mathrm{wt} \%$, to $50 \mathrm{wt} \%$, and then to $30 \mathrm{wt} \%$. The TAC analysis shows that a standalone reactive distillation is more economical than a flowsheet with a pre-treatment unit. Process characteristics have been explored and the results show significant nonlinearity associated with reactive distillation columns for all four different acid concentrations. A systematic design procedure is devised to control reactive distillation columns by temperature control. Reasonable control performance can be achieved. A further improvement can be made by incorporating feedforward control for feed flow disturbance. Finally, one-temperature-one composition control structure is also examined. Acceptable control performance can be obtained while maintaining acetate composition.
\end{abstract}

Key Words: reactive distillation, esterification, acetic acid recovery, process control, temperature control, nonlinearity measure.

\section{INTRODUCTION}

Dilute acetic acid solutions are often produced in many chemical processes, manufacturing of terephthalic acid, dimethyl terephthalate, cellulose ester, and acetate rayon (Xu et al., 1999a, 1999b; Saha et al., 2000; Chien et al., 2004; Hung et al., 2005b). Typically, the acetic acid concentration ranges from $70 \mathrm{wt} \%$ to $35 \mathrm{wt} \%$ and possibly down to $2-6 \mathrm{wt} \%$ for wood distillation. Generally, two approaches can be taken to treat the dilute acid. One approach is the acetic acid dehydration using simple distillation or heterogeneous azeotropic distillation as discussed in detail by Chien et al. (2004). A different route is to convert dilute acetic acid into useful chemicals such

*Corresponding author. (Tel: 886-2-3365-1759; Fax: 886-23366-3037; Email: ccyu@ntu.edu.tw)

W. J. Hung, I. K. Lai, H. P. Huang, and C. C. Yu are with the Department of Chemical Engineering, National Taiwan University Taipei 106, Taiwan.

S. B. Hung and M. J. Lee are with the Department of Chemical Engineering, National Taiwan University of Science and Technology Taipei 106, Taiwan. as acetates, which has been explored by several researchers (Xu et al., 1999a, 1999b; Saha et al., 2000; Hung et al., 2005b). Generally, reactive distillation is used for converting dilute acid into acetate and the conversion of the acid ranges from $60-80 \%$ as shown in the studies of Saha et al. (2000) and Xu et al. (1999a; 1999b). Hung et al. (2005b) explore the process chemistries based on the total annual cost (TAC) and they conclude that amyl alcohol is an ideal solvent for converting the dilute acid to amyl acetate and this offers great economic potential as compared to the cost of acetic acid. Amyl acetate has been used in industries as a solvent, an extractant, a polishing agent etc. Design and control of amyl acetate using pure acetic acid has been studied by Chiang et al. (2002) and Huang and Yu (2003). The above mentioned amyl acetate reactive distillation columns have been designed for "neat" operation. That is an exact stoichiometric amount of alcohol and acid is processed in one column such that high purity product can be obtained with an almost $100 \%$ conversion, as opposed to excess reactant design. This imposes stringent requirements on the control system design. 
Despite the great economic potential of a steadystate perspective, the operability of four reactive distillation columns with $100 \mathrm{wt} \%, 75 \mathrm{wt} \%, 50 \mathrm{wt} \%$, and $30 \mathrm{wt} \%$ is explored. First, process characteristics, such as nonlinearity measure and possible output multiplicities, are studied. Next, a systematic design procedure is devised for dual-temperature control and potential advantage of feedforward control is also shown. In order to maintain acetate product specification, composition control is also explored. The results indicate that acceptable control performance can be obtained for all different purity levels of acetic acid.

\section{PROCESS ANALYSIS}

\section{Optimal Steady-State Design}

Hung et al. (2005b) examines the process chemistry for dilute acetic acid recovery using alcohols ranging from methanol to $n$-pentanol $\left(\mathrm{C}_{1}\right.$ to $\left.\mathrm{C}_{5}\right)$. The results indicate that amyl alcohol is the best solvent for recovery of dilute acetic acid using a single reactive distillation column (without pretreatment) based on steady-state economics. Following the steady-state design procedure of Tang et al. (2005), the optimum results are shown in Fig. 1. Table 1 summarizes the optimal steady-state design for four different acid purity levels: $30 \mathrm{wt} \%, 50 \mathrm{wt} \%, 75 \mathrm{wt} \%$, and $100 \mathrm{wt} \%$. Product specification for the acetates is set to 99 mol\% with a production rate of $50 \mathrm{kmol} / \mathrm{hr}$.

It is interesting to note that the column diameter increases as HAc becomes more and more dilute. The reason for that is the column diameter is set by the vapor rate. That implies that as HAc concentration decreases, a reactive distillation with larger reactors with fewer equilibrium stages is preferred from a steady-state economic perspective for the amyl acetate system. But the Damköhler number $(D a)$ actually drops from 9.8 to 2, because of a larger vapor/ liquid traffic.

\section{Nonlinearity and Output Multiplicity}

The manipulated variables are determined to evaluate process nonlinearity for the amyl acetate process. The tray temperatures are treated as state variables. The manipulated variables are the heat input $Q_{R}$ and feed ratio $F R$, respectively. First, the upper and lower bounds of the steady-state gains between the tray temperatures and the manipulated variables $\left(Q_{R}\right.$ and $\left.F R\right)$ are obtained for a range of input variations. In this work, $-5 \%$ to $+5 \%$ changes in the heat input $\left(Q_{R}\right)$ and $-1 \%$ to $+1 \%$ changes in the feed ratio are made. Note that, for a truly linear system, the upper and lower bounds should coincide with each other. Fig. 2 clearly shows that dilute acetic acid concentrations of $75 \mathrm{wt} \%$ and $50 \mathrm{wt} \%$ are more nonlinear than the other two cases of $100 \mathrm{wt} \%$ and 30 wt $\%$. Moreover, the "sign reversal" is also observed for the four cases under either $Q_{R}$ or $F R$ change. The results presented here are rather unconventional, because chemical processes are known to be quite nonlinear, but not to this degree in such a consistent manner. Two measures are used to differentiate the degree of nonlinearity. One obvious choice is the fraction of sign reversal for all tray temperatures. In this regard, the case of $75 \mathrm{wt} \%$ HAc composition indicates that more than half of the trays show sign reversal in which almost half of the tray temperatures exhibit the "sign reversal". Table 2 summarizes the fraction of sign changes for all four cases. The second nonlinearity indicator is $\phi^{N}$ which was first proposed by Allgower for dynamic systems and further studied by Hernjak and Doyle (2003) under feedback. Schweickhardt and Allgower $(2004 ; 2005)$ give an updated summary on nonlinearity measures. The measure ranges from 0 to $1, \phi^{N}=0$ implies a linear process and $\phi^{N}=1$ means a highly nonlinear system. Following Hung et al. (2005a), we only consider steady-state (e.g., can be viewed as the nonlinearity measure for a static function) and the upper bound of the nonlinear measure can be computed from:

$$
\phi^{N}=\frac{\left\|\bar{G}-G_{+}\right\|_{2}}{\left\|G_{+}\right\|_{2}}=\frac{\left\|\bar{G}-G_{-}\right\|_{2}}{\left\|G_{-}\right\|_{2}}
$$

The vector $G$ corresponds to tray temperatures throughout the column, $G_{+}$is the upper bound of the static nonlinear function and $G_{-}$is the lower bound. Because we treat two manipulated inputs separately, two $\phi^{N}$, s are available for a given system. In this work, the 2-norm is used to compute $\phi^{N}$ and each manipulated variable is considered separately. The detailed definition and derivation are given in Hung et al. (2005a).

In addition to the trays' temperatures, we are also interested in the behavior of product composition for a range of input changes. Fig. 3 shows how temperatures and compositions change with the manipulated inputs and the dashed line in Fig. 3 indicates the nominal steady-state. The compositions for the cases of $75 \mathrm{wt} \%$ and $50 \mathrm{wt} \%$ HAc feed exhibit input multiplicity for the feed ratio variation. If a temperature, i.e., $\mathrm{T}_{15}$ or $\mathrm{T}_{10}$, is used instead, the input multiplicity cannot be eliminated completely. The multiplicity analysis indicates that the composition control of the aqueous acetic acid of $75 \mathrm{wt} \%$ and 50 wt $\%$ can be difficult.

The analysis presented here clearly indicates that the reactive distillation systems exhibit severe openloop nonlinearity which includes significant portions 


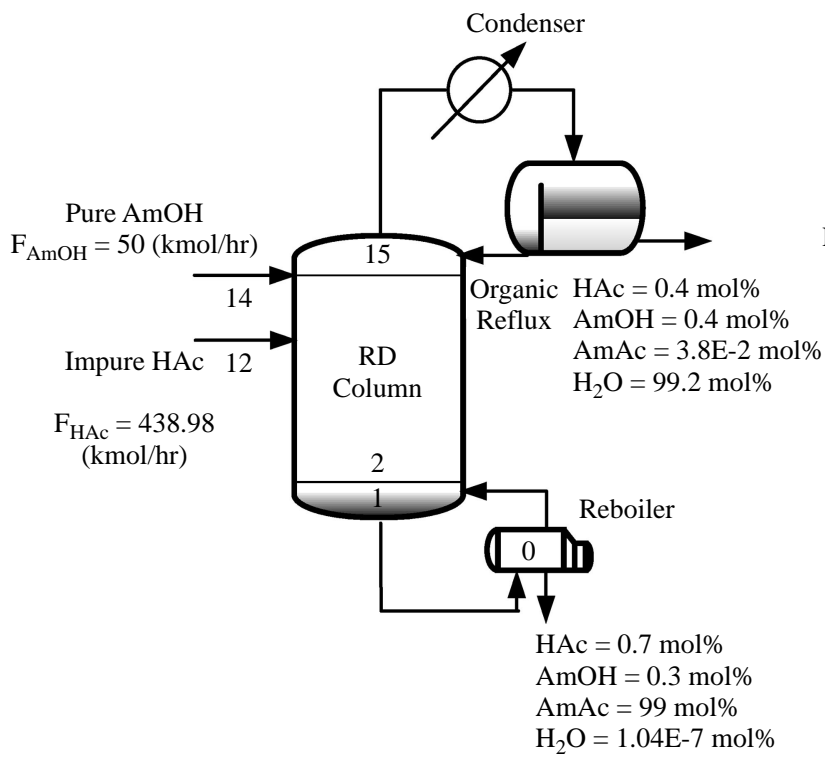

(A) $30 \mathrm{wt} \%$

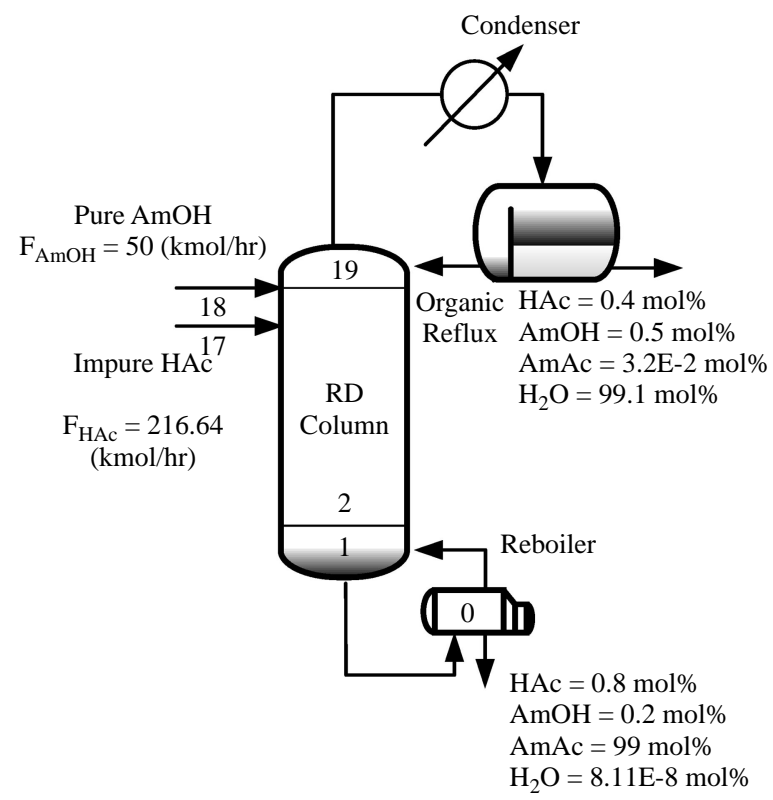

(B) $50 \mathrm{wt} \%$

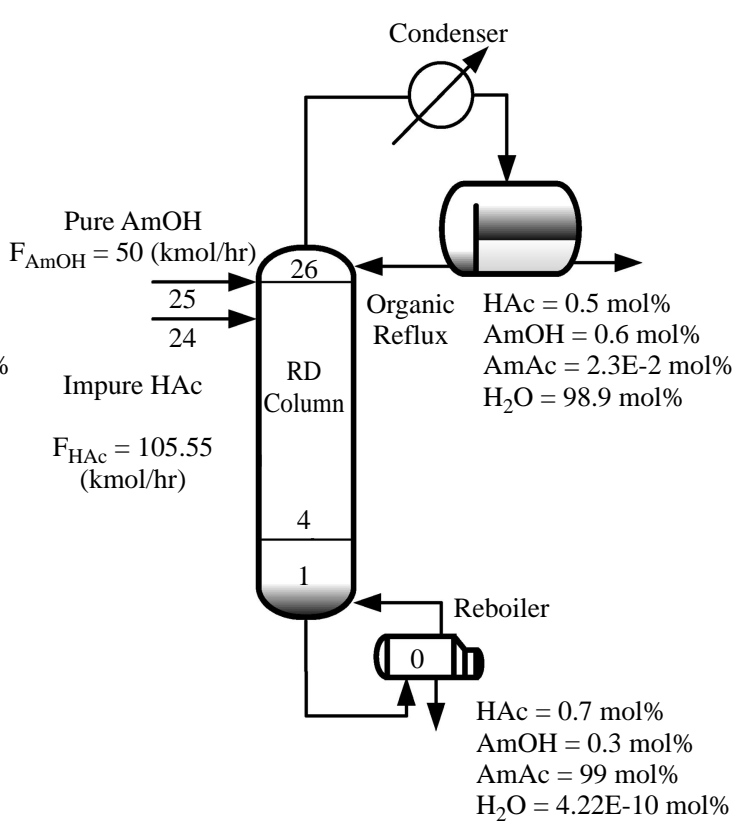

(C) $75 \mathrm{wt} \%$

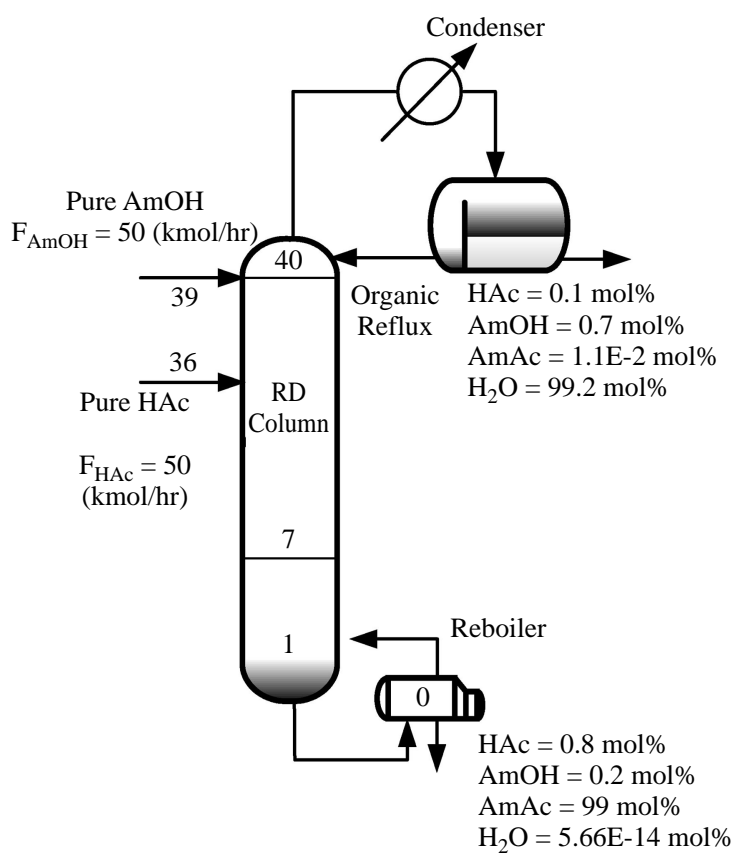

(D) $100 \mathrm{wt} \%$

Fig. 1 Optimized process flowsheets for aqueous acetic acid recovery via single reactive distillation column using amyl alcohol

of sign reversal, extremely large values of Allgower's nonlinearity measure, $\phi^{N}$, and input multiplicity. Under this circumstance, control structure design becomes important.

\section{DUAL - TEMPERATURE CONTROL}

\section{Control Structure Design}

In this section, a systematic approach (Hung, 2005a) is used for the control structure design. In order to maintain the stoichiometric balance, two temperatures are controlled. One is used to maintain the acetate composition and the other is to prevent accumulation of unreacted reactants. Note the overhead water composition is determined by the phase-split of the liquid-liquid equilibrium while making the or- 
Table 1 Optimal steady-state operating conditions and total annual cost (TAC) for recovery acetic acid with reactive distillation

\begin{tabular}{|c|c|c|c|c|}
\hline Case No of HAc fraction in the feed & $\begin{array}{c}100 \mathrm{wt} \% \\
(100 \mathrm{~mol} \%)\end{array}$ & $\begin{array}{c}75 \mathrm{wt} \% \\
(47.4 \mathrm{~mol} \%)\end{array}$ & $\begin{array}{c}50 \mathrm{wt} \% \\
(23.1 \mathrm{~mol} \%)\end{array}$ & $\begin{array}{c}30 \mathrm{wt} \% \\
(11.4 \mathrm{~mol} \%)\end{array}$ \\
\hline Total No. of trays including the reboiler & 41 & 27 & 20 & 16 \\
\hline No. of trays in stripping section $\left(N_{S}\right)$ & 6 & 3 & 1 & 1 \\
\hline No. of trays in reactive section $\left(N_{r x n}\right)$ & 33 & 22 & 17 & 13 \\
\hline No. of trays in rectifying section $\left(N_{R}\right)$ & 1 & 1 & 1 & 1 \\
\hline Reactive trays & $7 \sim 39$ & $4 \sim 25$ & $2 \sim 18$ & $2 \sim 14$ \\
\hline Acetic acid feed tray & 36 & 24 & 17 & 12 \\
\hline Pentanol feed tray & 39 & 25 & 18 & 14 \\
\hline Feed flow rate of acid $(\mathrm{kmol} / \mathrm{hr})$ & 50 & 50 & 50 & 50 \\
\hline Feed flow rate of pentanol $(\mathrm{kmol} / \mathrm{hr})$ & 50 & 50 & 50 & 50 \\
\hline Top product flow rate $(\mathrm{kmol} / \mathrm{hr})$ & 49.96 & 105.91 & 217.43 & 440.63 \\
\hline Bottom product flow rate $(\mathrm{kmol} / \mathrm{hr})$ & 50.03 & 49.64 & 49.21 & 48.35 \\
\hline Reflux flow rate $(\mathrm{kmol} / \mathrm{hr})$ & 52.23 & 48.16 & 71.79 & 139.26 \\
\hline Bottom vapor flow rate $(\mathrm{kmol} / \mathrm{hr})$ & 122.62 & 175.01 & 323.13 & 651.62 \\
\hline \multicolumn{5}{|l|}{$X_{D, a q}$} \\
\hline acid & 0.0010 & 0.00459 & 0.00385 & 0.00372 \\
\hline alcohol & 0.00711 & 0.00645 & 0.00506 & 0.00411 \\
\hline acetate & 0.00011 & 0.00023 & 0.00032 & 0.00038 \\
\hline water & 0.99178 & 0.98873 & 0.99076 & 0.99179 \\
\hline \multicolumn{5}{|l|}{$X_{B}$} \\
\hline acid & 0.00805 & 0.00697 & 0.00765 & 0.00676 \\
\hline alcohol & 0.00195 & 0.00302 & 0.00232 & 0.00323 \\
\hline acetate & 0.99000 & 0.99000 & 0.99000 & 0.99000 \\
\hline water & $5.66 \mathrm{e}-16$ & $4.22 \mathrm{e}-12$ & $8.11 \mathrm{e}-10$ & $1.04 \mathrm{e}-09$ \\
\hline Condenser duty (kW) & -1283.00 & -1845.36 & -3396.69 & -6789.01 \\
\hline Subcooling duty (kW) & -186.67 & -226.86 & -416.42 & -830.79 \\
\hline Reboiler duty (kW) & 1295.15 & 1840.41 & 3405.30 & 6876.45 \\
\hline Column diameter $(\mathrm{m})$ & 1.225 & 1.454 & 2.018 & 2.957 \\
\hline Condenser heat transfer area $\left(\mathrm{m}^{2}\right)$ & 23.85 & 35.70 & 71.21 & 144.22 \\
\hline Subcooling heat transfer area $\left(\mathrm{m}^{2}\right)$ & 21.86 & 26.74 & 52.42 & 105.88 \\
\hline Reboiler heat transfer area $\left(\mathrm{m}^{2}\right)$ & 36.49 & 51.86 & 95.95 & 193.76 \\
\hline Damköhler number $(D a)$ & 9.58 & 3.64 & 2.88 & 1.98 \\
\hline Total capital cost $(\$ 1000)$ & 790.24 & 794.00 & 1048.71 & 1518.65 \\
\hline Column & 404.26 & 343.39 & 378.66 & 470.85 \\
\hline Column trays & 69.44 & 58.83 & 71.45 & 102.01 \\
\hline Heat exchangers & 316.54 & 391.79 & 598.61 & 945.79 \\
\hline Total operating cost $(\$ 1000 /$ year $)$ & 167.51 & 227.93 & 414.61 & 826.01 \\
\hline Catalyst cost & 20.81 & 19.53 & 29.06 & 47.74 \\
\hline Energy cost & 146.70 & 208.41 & 385.54 & 778.27 \\
\hline TAC $(\$ 1000 /$ year $)(50 \mathrm{kmol} / \mathrm{hr}$ of AmAc) & 430.92 & 492.60 & 764.18 & 1332.23 \\
\hline
\end{tabular}

ganic phase totally refluxed. So it is not necessary to control a temperature or composition in the top section of the column. Two candidate manipulated variables are the feed ratio $(F R)$ and heat input to the reboiler $(Q)$. Because of significant uncertainty, e.g., input multiplicities and potential sign reversals, associated with the process, we would like to minimize the model information required for control sys- tem design. The decentralized control is preferred because we are not even certain about the sign of the gains for a given manipulated input, if the controlled variables are chosen appropriately. Then the nonsquare relative gain (NRG; Chang and $\mathrm{Yu}, 1990)$ is used to select temperature control trays. Next, the relative gain array (RGA; Bristol, 1966) is used for variable pairings. Finally, the relay feedback test (Shen 

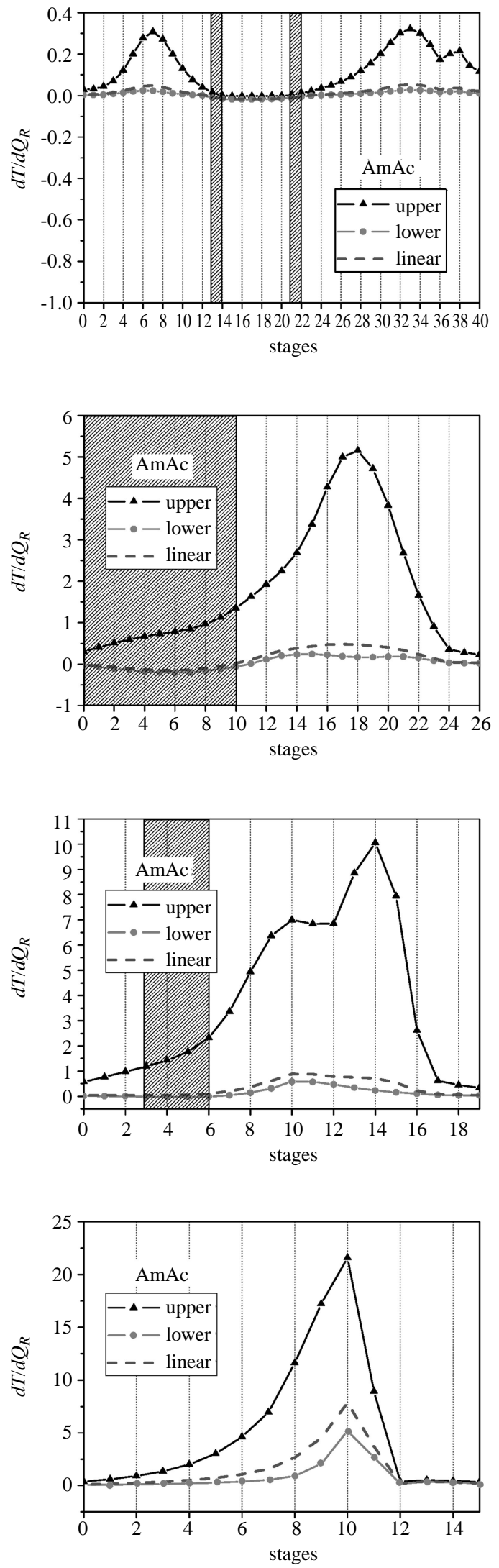

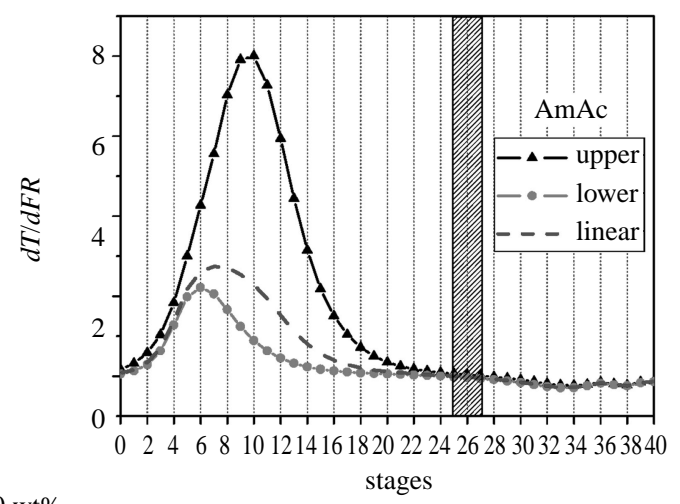

(a) $100 \mathrm{wt} \%$

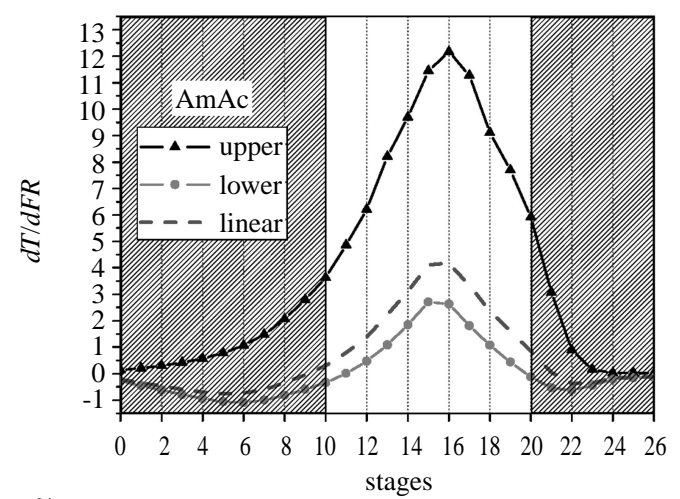

(b) $75 \mathrm{wt} \%$

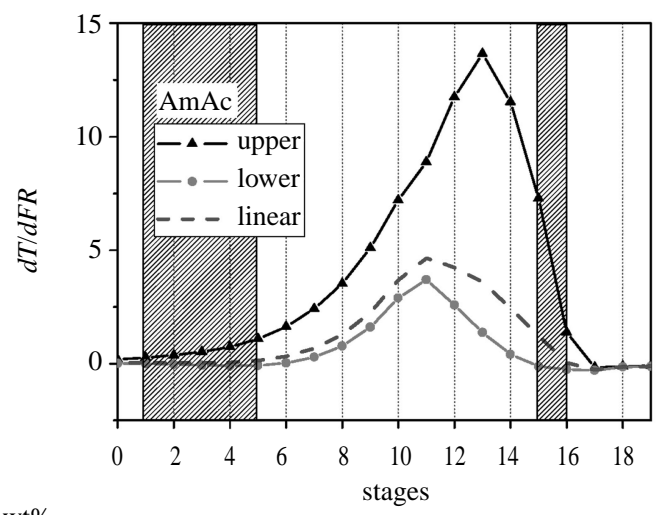

(c) $50 \mathrm{wt} \%$

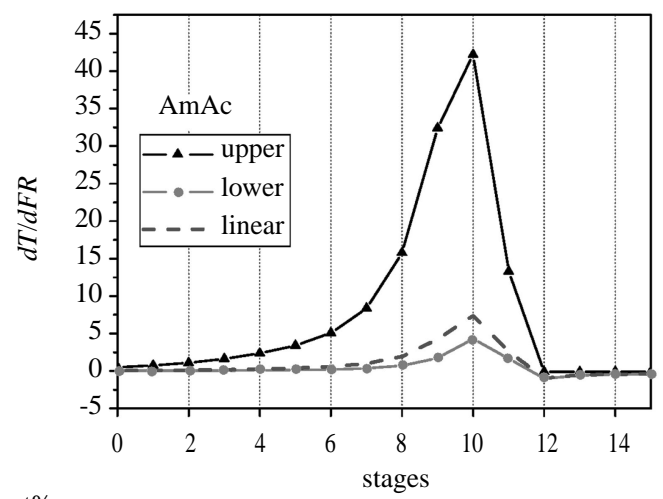

(d) $30 \mathrm{wt} \%$

Fig. 2 Upper and lower bounds of steady-state gains of all tray temperatures for $\pm 5 \%$ reboiler duty and $\pm 1 \%$ feed ratio changes and the sign reversal indicated as shaded areas 
Table 2. Fractions of sign reversal and nonlinearity measures for AmAc esterification with different feed compositions of acetic acid

\begin{tabular}{ccccccccc}
\hline System & $\begin{array}{c}\text { HAc } \\
\text { composition } \\
\text { in the feed }\end{array}$ & \multicolumn{3}{c}{$\begin{array}{c}\text { Fraction of sign } \\
\text { reversal }\end{array}$} & \multicolumn{2}{c}{$\begin{array}{c}\text { Nonlinearity measure } \\
\text { (Schweickhardt and } \\
\text { Allgower) }\end{array}$} & $\begin{array}{c}\text { Overall } \\
\text { Assessment*** }\end{array}$ \\
\hline AmAc & $100 \mathrm{wt} \%$ & 0.10 & 0.07 & 0.17 & 0.84 & 0.66 & 0.76 & $\mathrm{M}$ \\
& $75 \mathrm{wt} \%$ & 0.41 & 0.67 & 0.67 & 0.90 & 0.75 & 0.83 & $\mathrm{H}$ \\
& $50 \mathrm{wt} \%$ & 0.21 & 0.37 & 0.42 & 0.91 & 0.69 & 0.81 & $\mathrm{H}$ \\
& $30 \mathrm{wt} \%$ & 0 & 0 & 0 & 0.69 & 0.84 & 0.77 & $\mathrm{M}$ \\
\hline
\end{tabular}

*delete overlapping (from each input) trays

**taking as 2-norm of two inputs divided by two

***High (if the averaged value exceeds 0.5), Medium (if the averaged value exceeds 0.3 ), and Low (if the averaged value less than 0.3 ).

and $\mathrm{Yu}, 1994 ; \mathrm{Yu}, 1999)$ is used to find the ultimate gain $\left(K_{u}\right)$ and the ultimate period $\left(P_{u}\right)$ followed by the Tyreus-Luyben PI tuning rule. The tuning is carried out in a sequential manner on the process such that process interaction is taken into account in the identification-tuning steps. Table 2 summarizes the settings for all four cases. It can be seen that the heat input is paired with an upper section tray temperature and a lower section tray temperature is controlled by the feed ratio (e.g., $\mathrm{T}_{34}-Q_{R} \& \mathrm{~T}_{16}-F R$ for the case of $100 \mathrm{wt} \%$ HAc feed). Also note that a large reset time is associated with the feed ratio $(F R)$ loop and the reset time for the heat input loop is relatively small (Hung et al., 2005a; Cheng and Yu, 2005). This implies slow integration is employed to prevent possible stoichiometric imbalance. So, we have a fast heat input loop to take care of the disturbance, initially, followed by a gradual effort to prevent accumulation of unused reactants. Fig. 4 shows a typical control structure for the dual-temperature control.

\section{Results and Extensions}

Feed flow disturbance is used to evaluate the control performance of the temperature control for the amyl acetate system. Fig. 5 shows the dynamic responses for $\pm 20 \%$ production rate changes. Despite strong nonlinearity, at least in an open-loop sense, reasonable control can be achieved. It can be seen that significant transient product composition deviations (maximum deviation of 0.04 in mole fraction for $100 \mathrm{wt} \%$ and $0.06 \mathrm{~m}$.f. for $30 \mathrm{wt} \%$ ) are observed for the cases of $100 \mathrm{wt} \%$ and $30 \mathrm{wt} \%$ HAc feed, especially for $20 \%$ feed flow rate increase. Large swings in the temperature controlled trays are also evident with asymmetrical responses. The products composition, $X_{B, \text { acetate }}$, reaches steady-state in 15 hours. The results actually can be foreseen in the nonlinear analysis. For cases of $75 \mathrm{wt} \%$ and $50 \mathrm{wt} \%$ HAc feed, fast dynamics are attainable with a much smaller transient deviation (maximum deviation of less than 0.02 m.f.) as shown in Fig. 5. Furthermore, the process settles in 5 hours. Fig. 5 also shows asymmetrical responses in the product compositions $\left(X_{B, \text { acetate }}\right.$ and $\mathrm{X}_{\mathrm{D}, \mathrm{H}_{2} \mathrm{O}}$ ).

Because of large transient deviation for the cases of $100 \mathrm{wt} \%$ and $30 \mathrm{wt} \%$ HAc feed, the feedforward control is incorporated for, possibly, improved control performance. In the feedforward configuration, Fig. 6, the feed flow rate is fed forward to the heat input via a ratio control. Thus, the heat input can be adjusted in advance to prevent large deviations in the temperature as well as composition. Again, feed flow disturbance is also used for comparing the performance of these two control configurations (with and without feedforward control). Fig. 7 compares the dynamic responses for these two control structures for the cases of $100 \mathrm{wt} \%$ and $30 \mathrm{wt} \%$ HAc feed. The results show that the peak errors are reduced by factors of 3 and 10, respectively, as shown in Fig. 7. That implies that feedforward control is very effective for these highly nonlinear reactive distillation systems. Before leaving the section, it should be emphasized that, despite reasonable control performance, steady-state offsets in the acetate composition can be observed in the dual temperature control. The steady-state offsets range from 0.013 m.f. for $75 \mathrm{wt} \% \mathrm{HAc}$ feed to 0.0075 m.f. for $50 \mathrm{wt} \%$ HAc feed. In order to maintain product quality, composition control is explored next.

\section{COMPOSITION CONTROL}

Because of the steady-state offsets in the dualtemperature control, one may seek offset-free composition control for amyl acetate production using dilute acetic acid. Here, we choose to control the acetate product quality via composition control while 

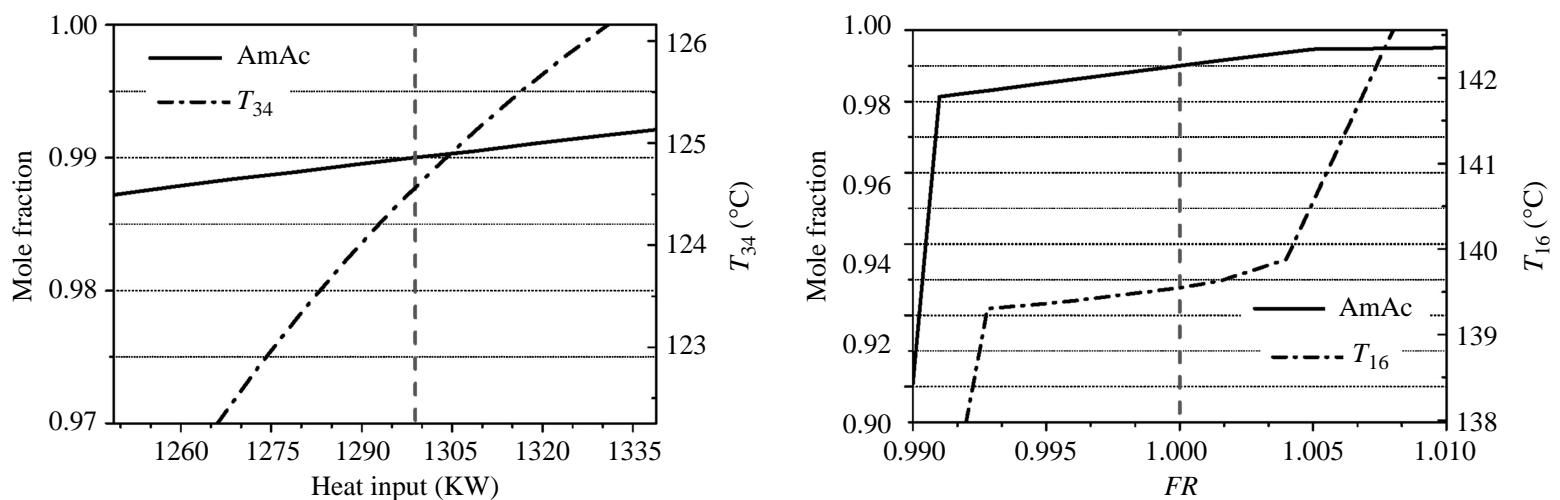

(a) $100 \mathrm{wt} \%$
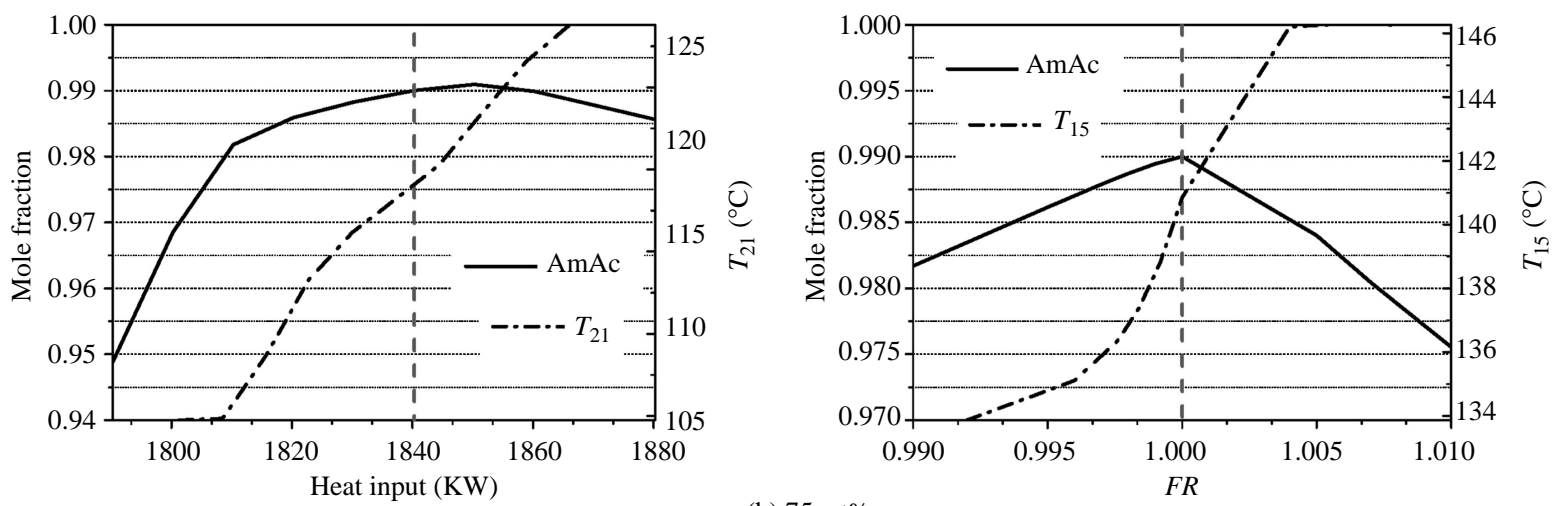

(b) $75 \mathrm{wt} \%$
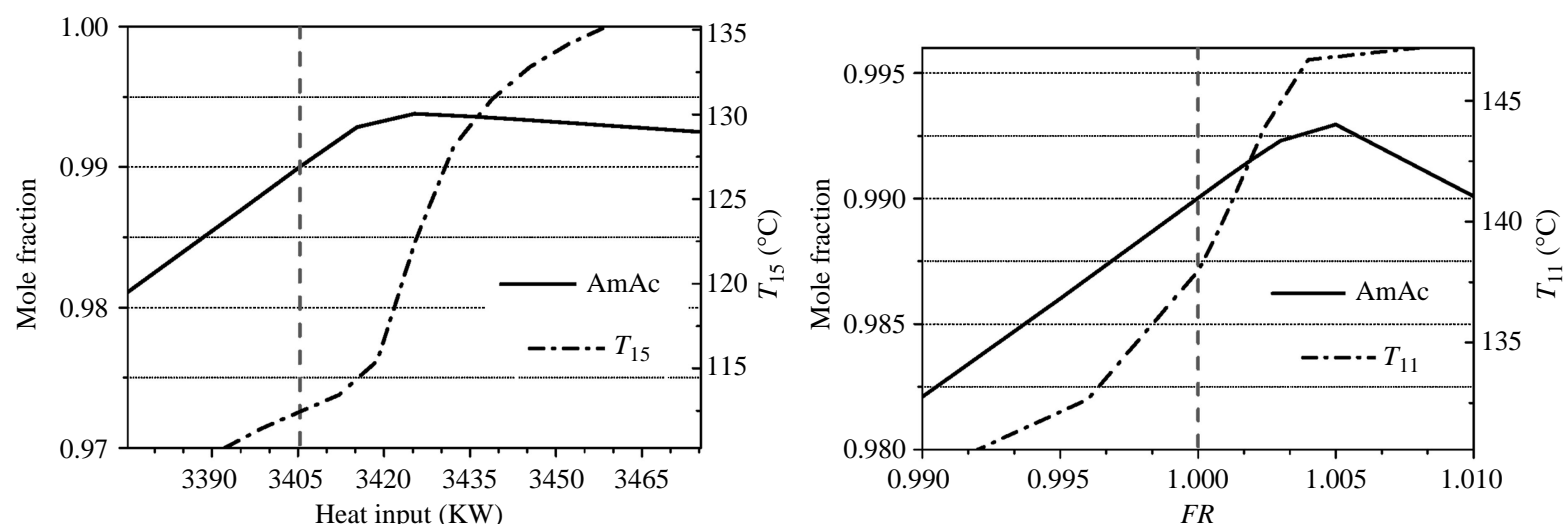

(c) $50 \mathrm{wt} \%$
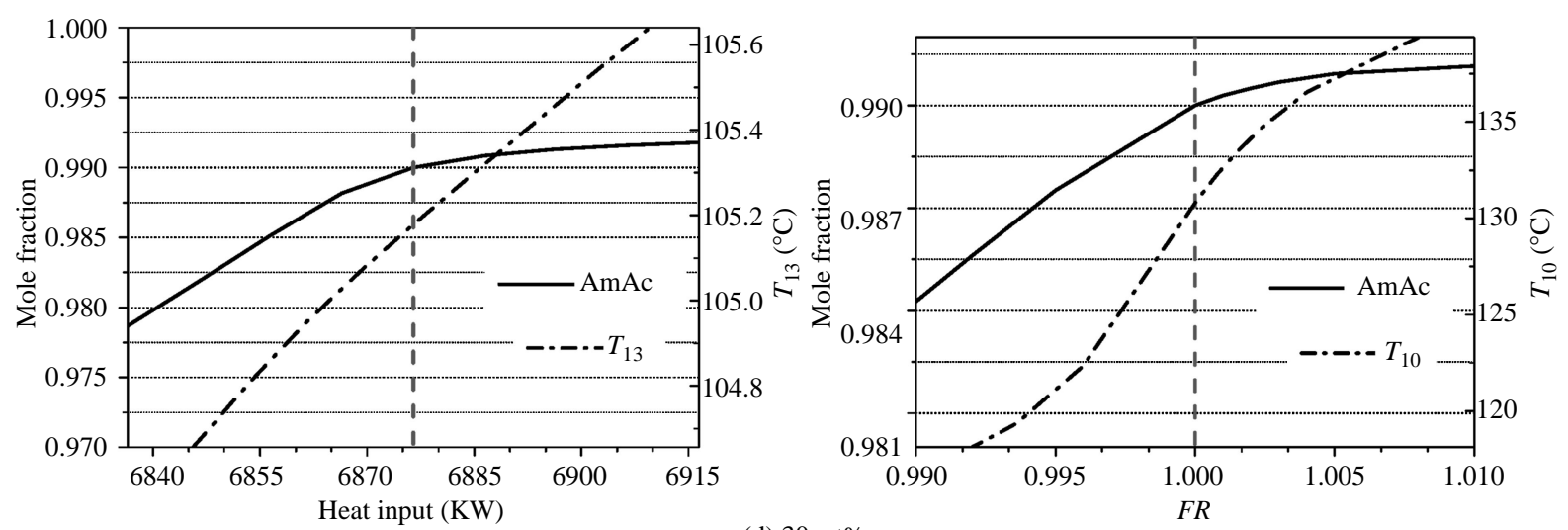

(d) $30 \mathrm{wt} \%$

Fig. 3 Trends of product compositions and temperature responses for a range of changes in the manipulated variables (heat input and feed ratio) and nominal design indicated by the dashed line 


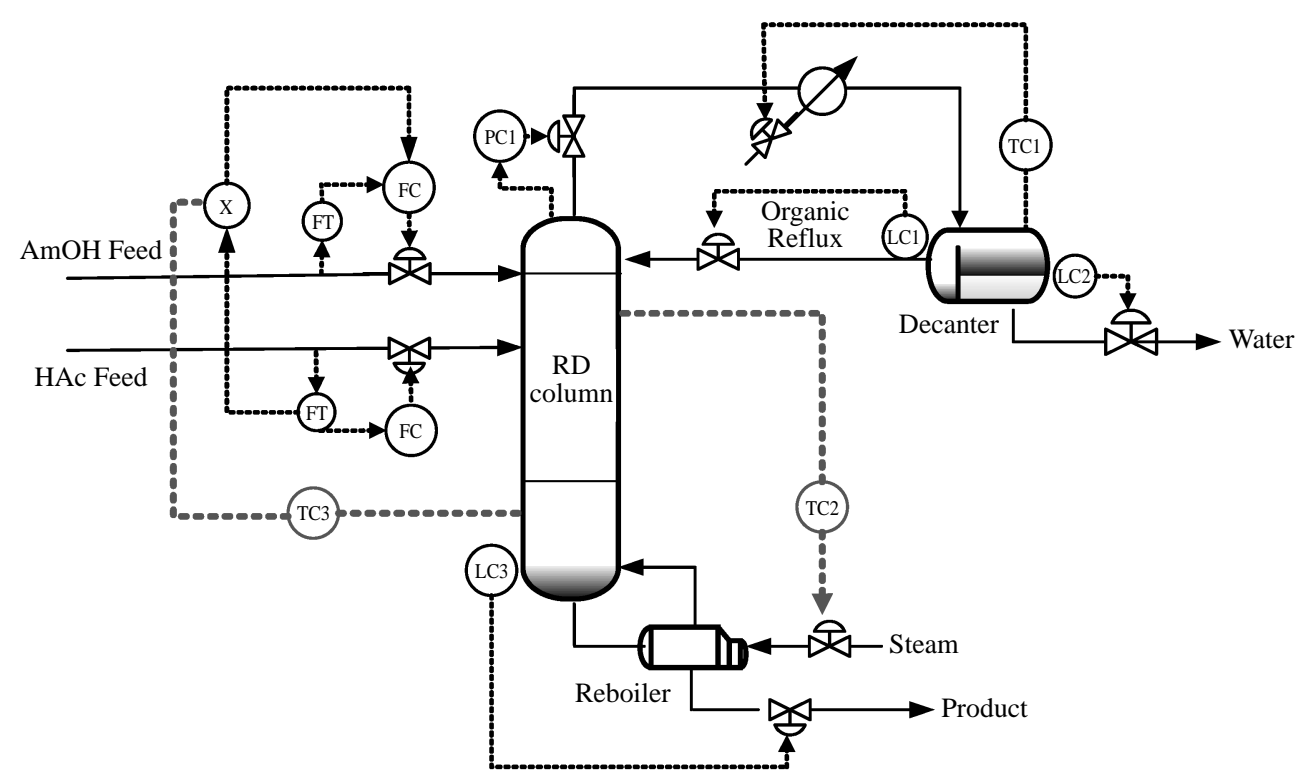

Fig. 4 Process flowsheet for temperature control configuration

keeping the stoichiometric balance using temperature as an indicator.

In the previous section, two temperature control trays are selected from the NRG analysis. Because the bottom product composition is one of the controlled variables, the other controlled variable is the temperature further away from the acetate withdrawal point. Therefore, a composition analyzer is substituted for the temperature in the lower section of the column. This becomes a one- temperature- onecomposition control scheme as shown in Fig. 8. Once the manipulated variables and controlled variables are determined, the RGA is used to provide appropriate pairing for the decentralized control. Note that 4 minutes of analyzer dead time is assumed for the composition loop. Next, the sequential relay feedback tests and autotuning are performed to find the PI controller settings. Table 4 gives the steady-state gain matrices, RGA, and PI setting all four cases. There are two manipulated variables, heat input and feed ratio, for one temperature and one composition control. The results reveal that the composition is controlled with the heat inputs and the feed ratio is used for temperature control. However, unlike the dual-temperature control scheme, the heat input loop is slowed down by the dead time associated with the analyzer dead time and the reset times now range from 40 minutes to 66 minutes as compared to that of a single digit in the dual-temperature control configuration while the reset time for the feed ratio loops remains quite large (Table 4 ). We expect that the control responses will be much slower than those of the dual-temperature control cases.

Feed flow disturbance is used to evaluate the dynamic performance of one- temperature- one- composition control for recovery of dilute acetic acid. Fig. 9 shows the dynamic responses for $\pm 20 \%$ feed flow rate changes. Asymmetric responses can be clearly seen for all four cases and they take, at least, 15 hours to reach steady-state. Despite offset free performance, the closed-loop performance is generally poorer than that of the dual-temperature control counterpart. This is especially true for the cases of $75 \mathrm{wt} \%$ and $50 \mathrm{wt} \%$ HAc feed where fast transient is replaced by slow dynamics, in order to eliminate steady-state offset. The results presented here clearly indicate the importance of rapid response to disturbance of a control system for these highly nonlinear processes. Once the controlled variables drift away from set point, it takes a great effort to bring them back to set point. This is quite similar to what we have seen in extremely high-purity distillation columns.

\section{CONCLUSIONS}

This work explores the dynamics and control for the recovery of dilute acetic acid (ranging from 100 wt $\%$ to $30 \mathrm{wt} \%$ ) via esterification using reactive distillation. Despite great economic incentives, it is not clear whether these reactive distillation systems possess good operability. First, two measures are used to analyze the degree of nonlinearity for all four cases. One is the fraction of sign reversal for all tray temperatures and the other is the Allgower's nonlinearity measure, $\phi^{N}$. Results show that significant nonlinearity and possible steady-state sign reversal are observed for all four systems. A systematic design procedure is used to design the control structures. Simulation 


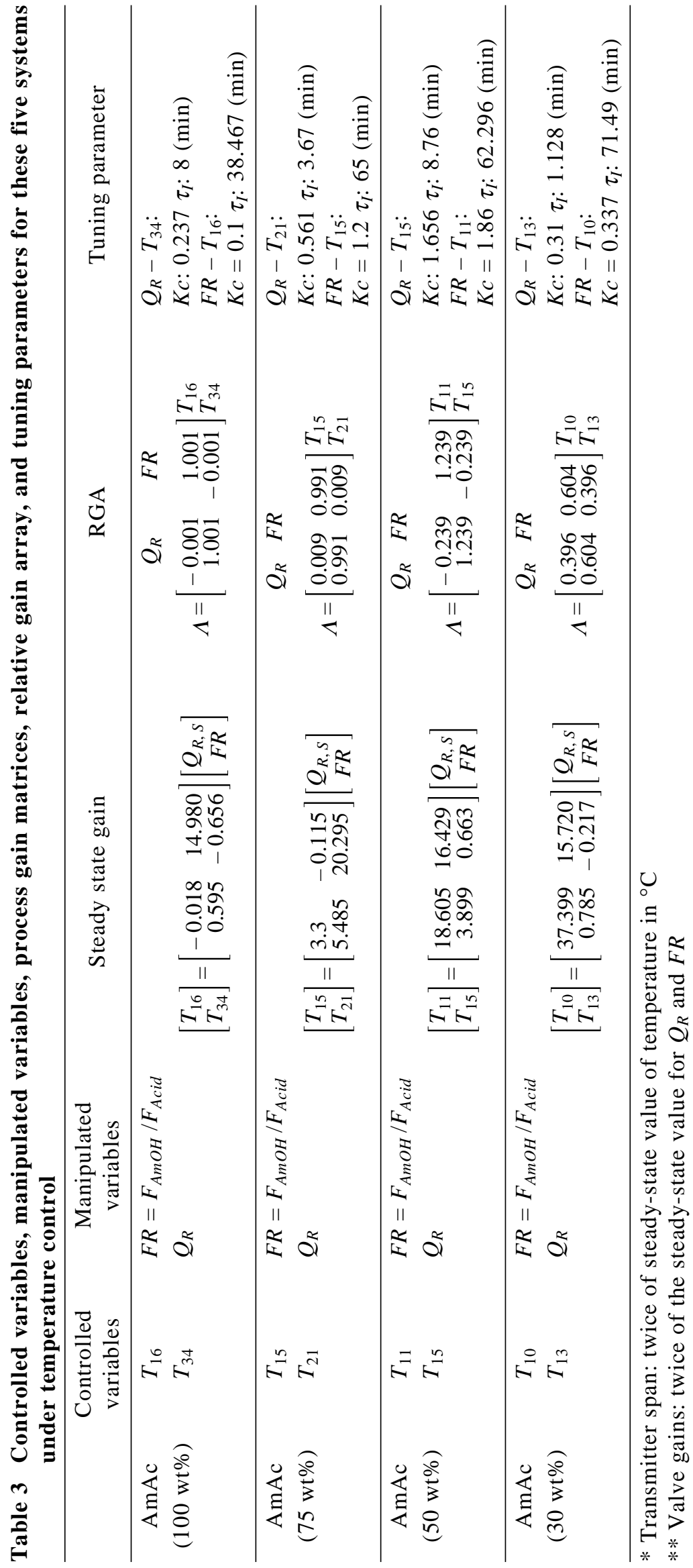



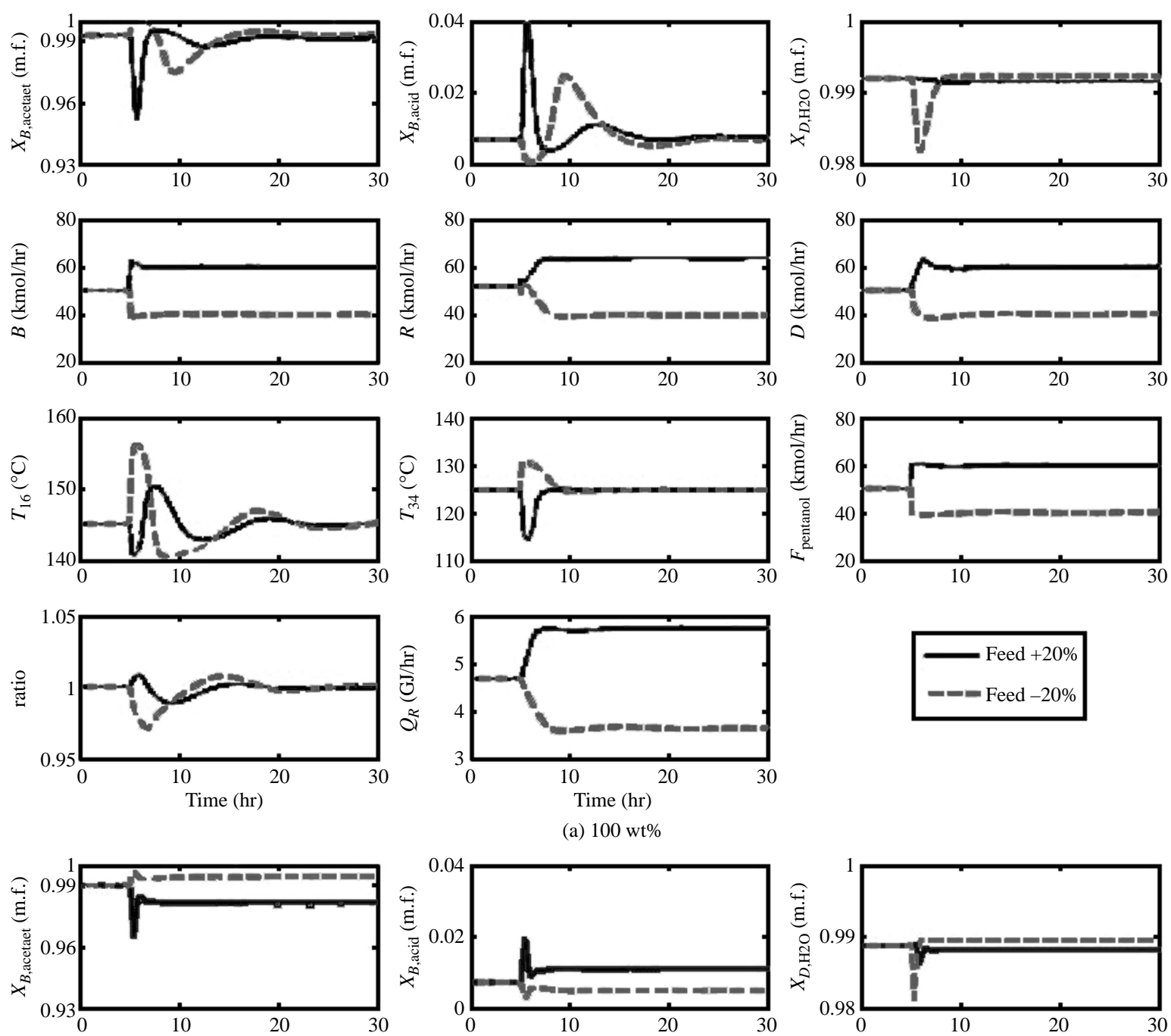

(a) $100 \mathrm{wt} \%$
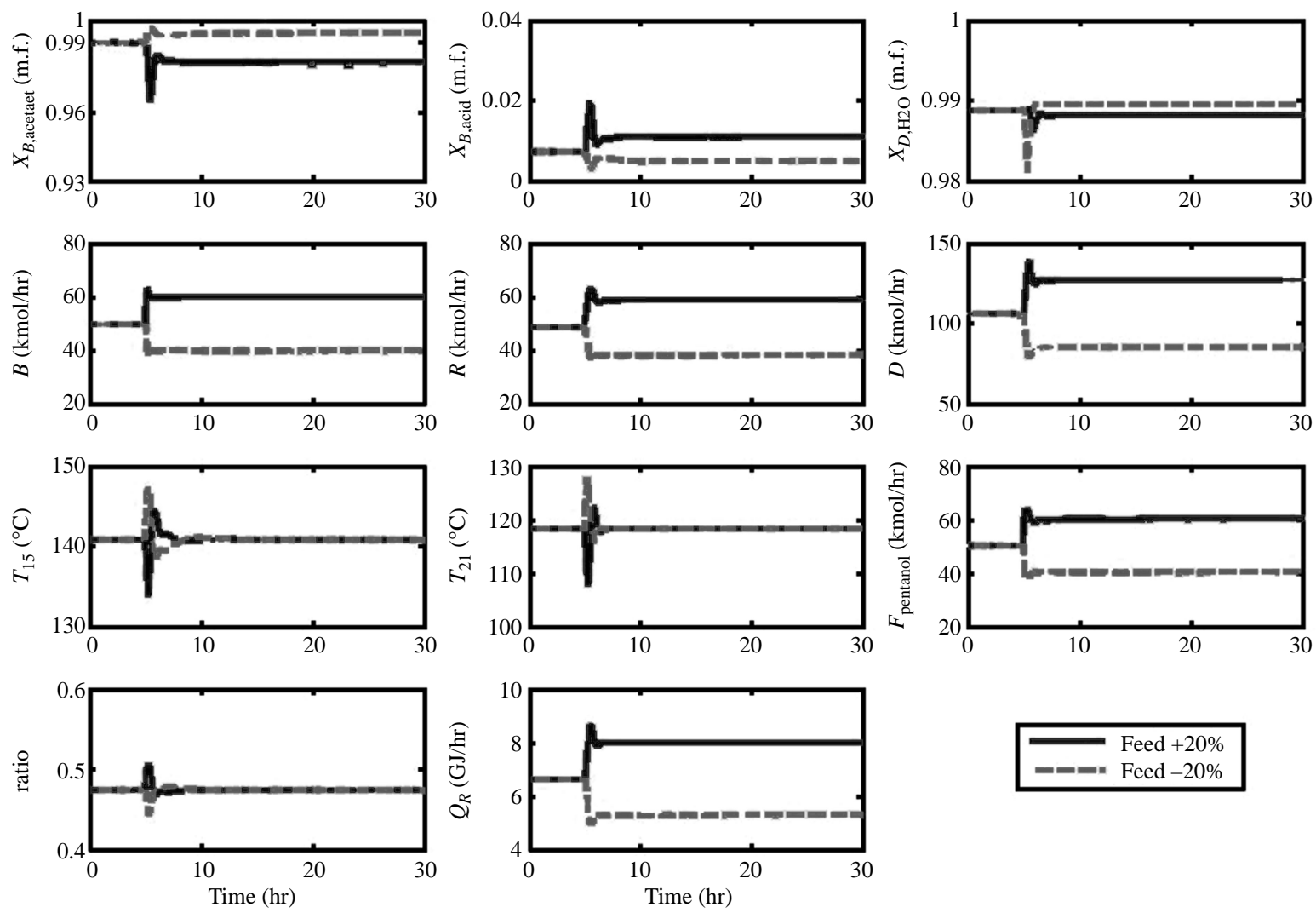

(b) $75 \mathrm{wt} \%$

Fig. 5 Temperature control responses for $\pm 20 \%$ production rate changes for AmAc esterificaiton with different feed compositions of acetic acid 

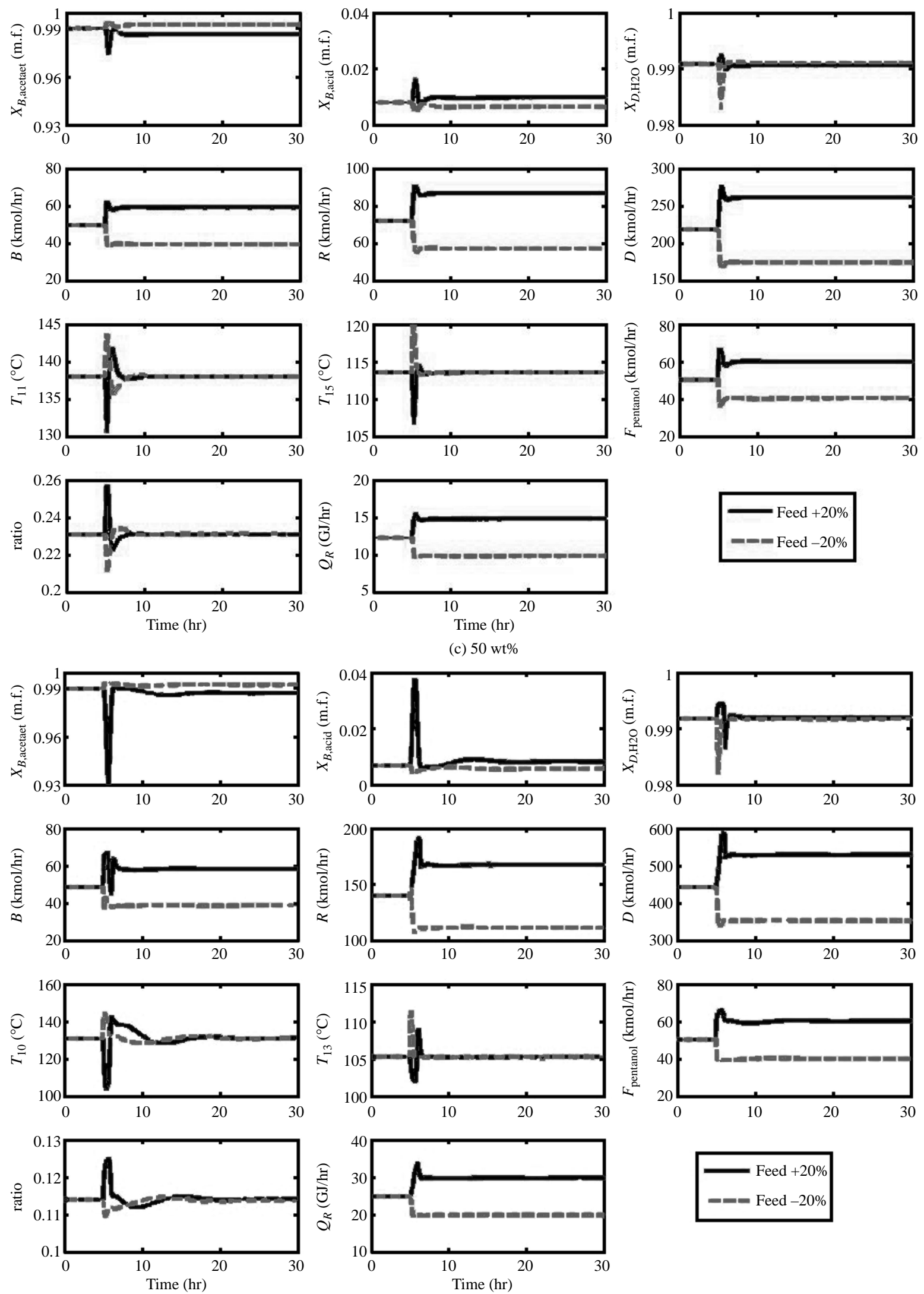

Fig. 5 Temperature control responses for $\pm 20 \%$ production rate changes for AmAc esterificaiton with different feed compositions of acetic acid (Continue) 


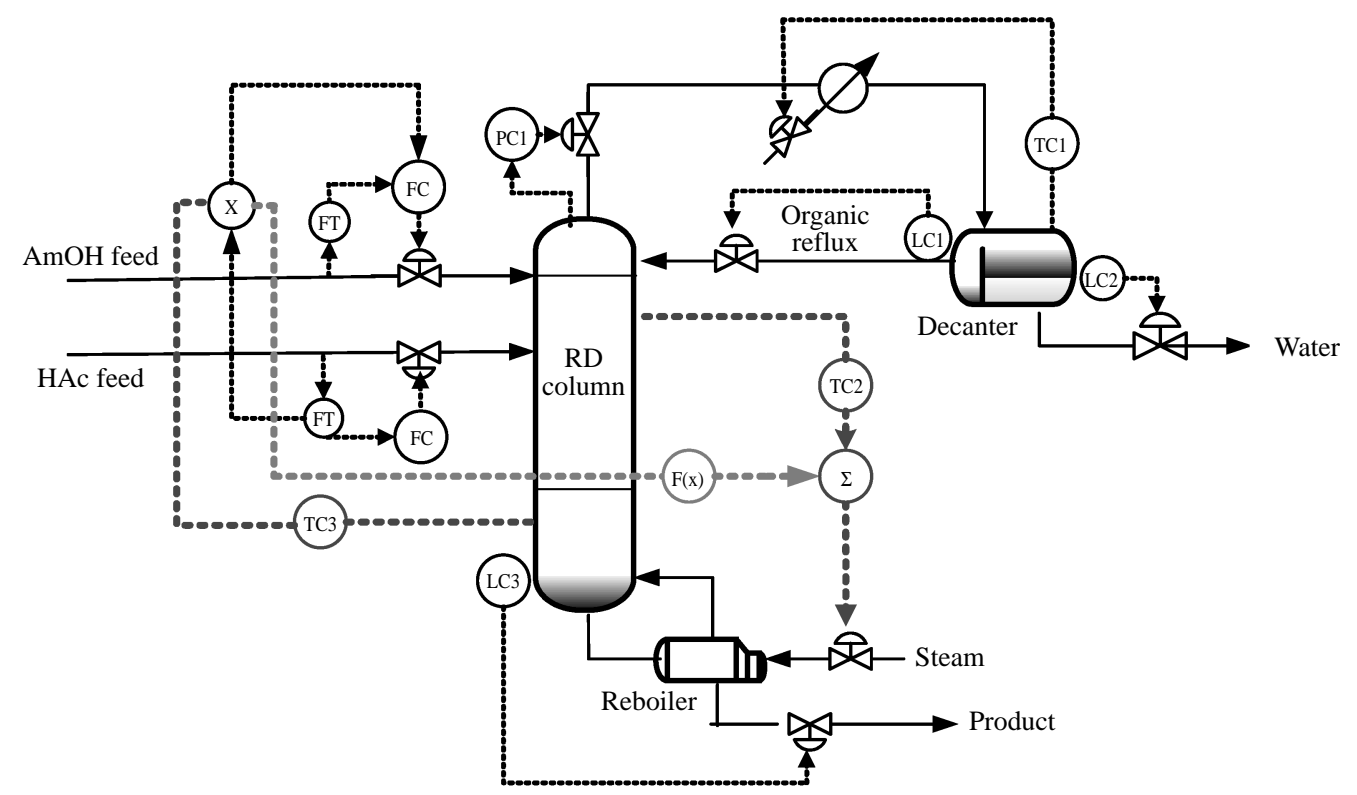

Fig. 6 Process flowsheet for feedforward control configuration

results reveal that a dual-temperature control structure works reasonably well for all four cases, especially for $75 \mathrm{wt} \%$ and $50 \mathrm{wt} \%$ HAc feed. A feedfoward scheme is incorporated to improve the control performance and the results clearly show much improved control can be obtained for $100 \mathrm{wt} \%$ and $30 \mathrm{wt} \%$ HAc feed compositions. Finally, the one- temperature- onecomposition control scheme is proposed and the offset-free composition responses are observed, however, with slower dynamics. A final word is that one can combine the advantages of the fast-and-less-accurate temperature control with slow-and-more-accurate composition control for better control performance with a parallel cascade type of control structure.

\section{ACKNOWLEDGMENTS}

This paper is dedicated to the late Professor Y. P. Shih, a mentor for generations to follow and a pioneer in process control research. His influence in chemical engineering research remains strong ten years after his passing. This work was supported by the Ministry of Economic Affairs under grant 93-EC17-A-09-S1-019.

\section{REFERENCE}

Bristol, E. H., 1966, “On a New Measure of Interaction for Multivariable Process Control," IEEE Transactions on Automatic Control, Vol. AC-11 Vol. 1, pp. 133-134.

Chang, J. W., and Yu, C. C., 1990, "The Relative Gain for Non-Square Multivariable Systems," Chemi- cal Engineering Science, Vol. 45, pp. 1309-1323.

Cheng, Y. C., and Yu, C. C., 2005, "Effects of Feed Tray Locations to the Design of Reactive Distillation and Its Implication to Control," Chemical Engineering Science, Vol. 60, No. 17, pp. 46614677.

Chiang, S. F., Kuo, C. L., Yu, C. C., and Wong, D. S. H., 2002, "Design Alternatives for Amyl Acetate Process: Coupled Reactor/Column and Reactive Distillation," Industrial and Engineering Chemistry Research, Vol. 41, No. 13, pp. 3233-3246.

Chien, I. L., Zeng, K. L., Chao, H. Y., and Liu, J. H., 2004, "Design and Control of Acetic Acid Dehydration System via Heterogeneous Azeotropic Distillation," Chemical Engineering Science, Vol. 59, No. 21, pp. 4547-4567.

Hernjak, N., and Doyle, F. J., 2003, "Correlation of Process Nonlinearity with Closed-Loop Disturbance Rejection," Industrial and Engineering Chemistry Research, Vol. 42, No. 20, pp. 46114619.

Huang, S. G., and Yu, C. C., 2003, "Sensitivity of Thermodynamic Parameter to the Design of Heterogeneous Reactive Distillation: Amyl Acetate Esterification," Journal of the Chinese Institute of Chemical Engineers, Vol. 34, No. 3, pp. 345355 .

Hung, S. B., Tang, Y. T., Chen, Y. W., Lai, I. K., and Hung, W. J., 2005a, "Dynamics and Control of Reactive Distillation Configurations for Acetic Acid Esterification," AIChE Journal (in press).

Hung, W. J., Lai, I. K., Hung, S. B., Chen, Y. W., Huang, H. P., Yu, C. C., and Lee, M. J., 2005b, 

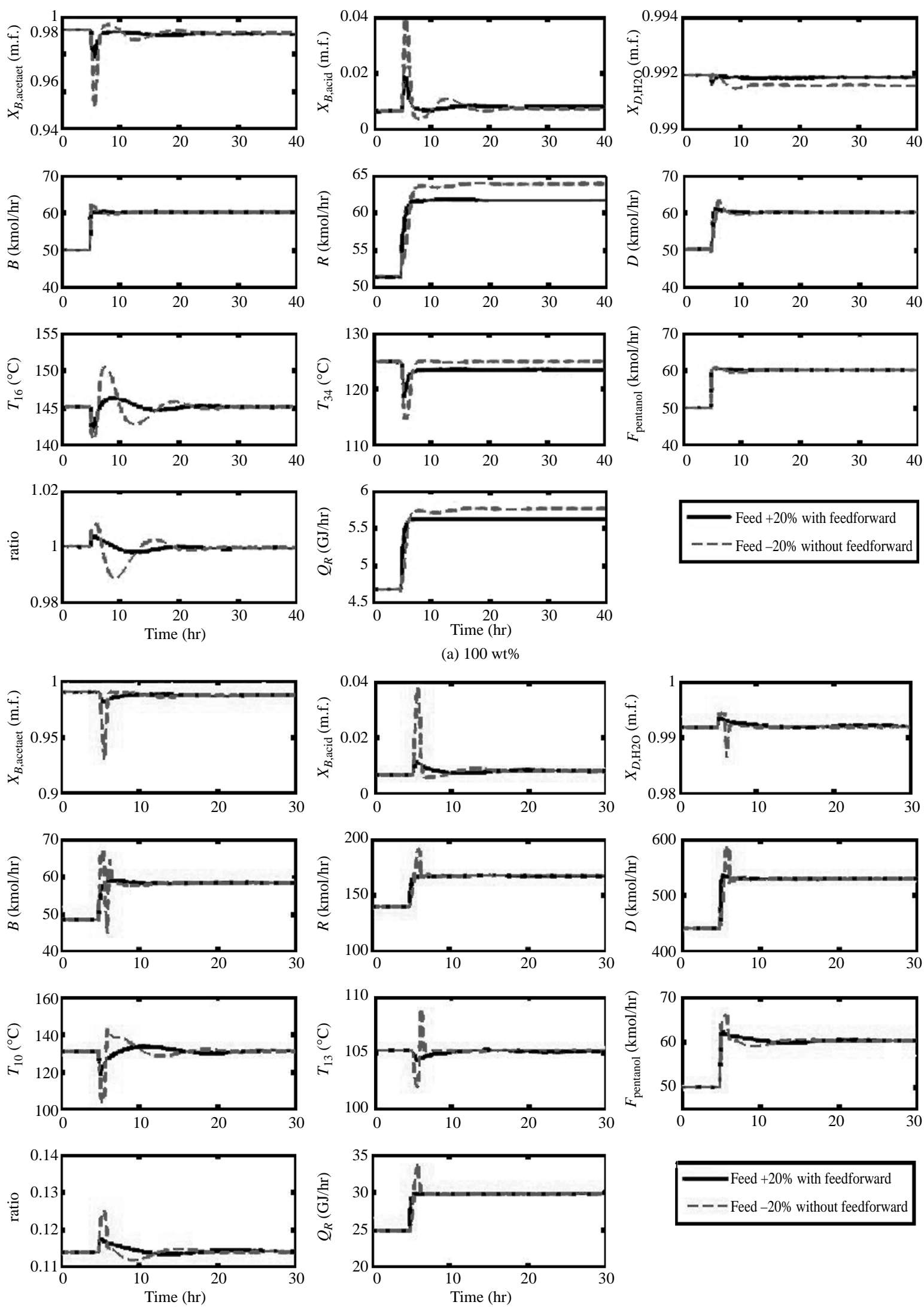

- Feed $+20 \%$ with feedforward

- - Feed $-20 \%$ without feedforward

(b) $30 \mathrm{wt} \%$

Fig. 7 Feedforward control responses for $\pm 20 \%$ production rate changes for AmAc esterification with different feed compositions of acetic acid 


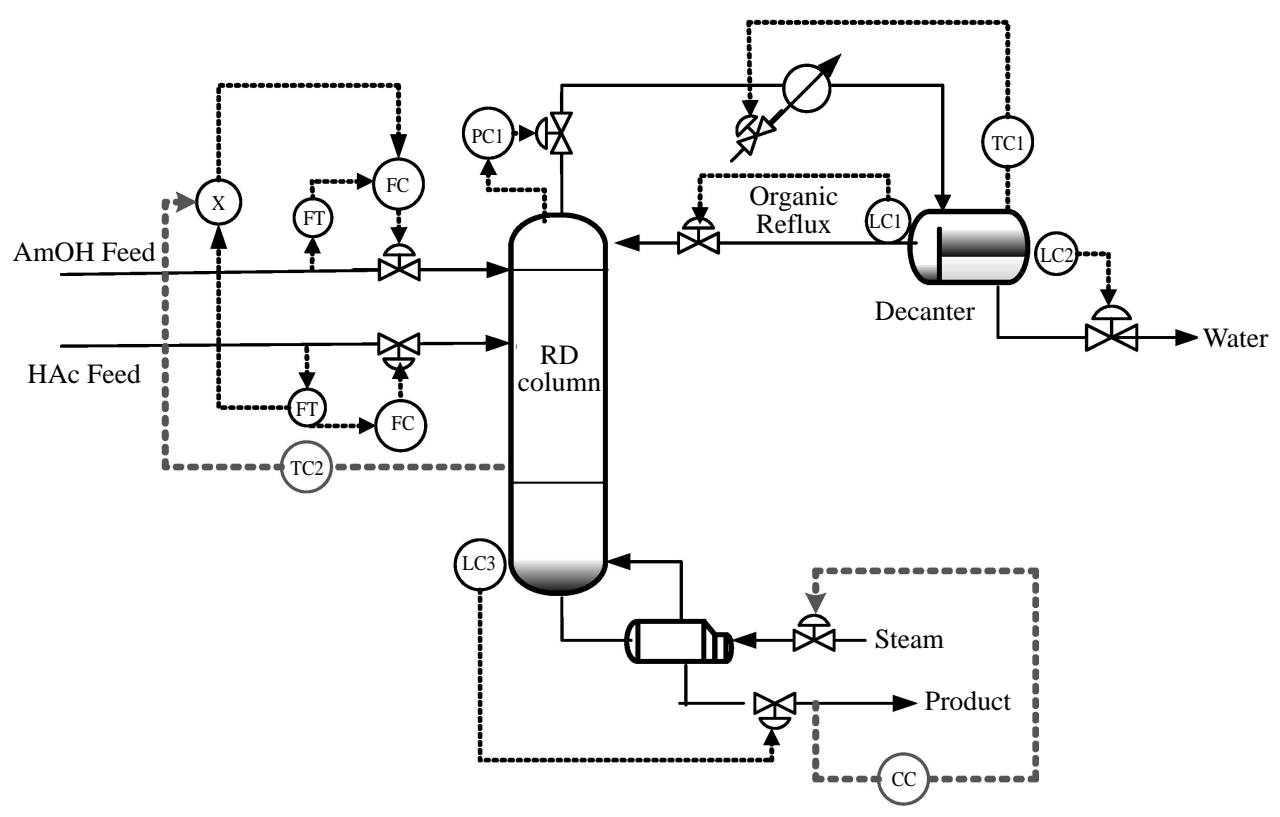

Fig. 8 Process flowsheet for one-temperature-one-composition control configuration

"Process Chemistry and Design Alternatives for Recovery of Dilute Acetic Acid through Esterification in Reactive Distillation," Industrial and Engineering Chemistry Research (submitted).

Menold, P. H., Allgöwer, F., and Pearson, R. K., 1997,

"Nonlinear Structure Identification of Chemical Processes," Computers and Chemical Engineering, Vol. 21, pp. S137-S142.

Saha, B., Chopade, S. P., and Mahajani, S. M., 2000, "Recovery of Dilute Acetic Acid through Esterification in a Reactive Distillation Column," $\mathrm{Ca}$ talysis Today, Vol. 60, No. 1, pp. 147-157.

Schweickhardt, T., and Allgower, F., 2004, "Quantitative Nonlinearity Assessment: An Introduction to Nonlinearity Measure," Integration of Process Design and Control, P. Seferlis, and M. C. Georgiadis eds., Elsevier, Amsterdam, the Netherlands.

Schweickhardt, T., and Allgower, F., 2005, "Linear Modeling Error and Steady-state Behaviour of Nonlinear Dynamical Systems," Internal Report, Institute of System Theory in Engine-ering, University of Stuttgart, Stuttgart, Germany.

Shen, S. H., and Yu, C. C., 1994, "Use of Relay-Feedback Test for Automatic Tuning of Multivariable
Systems," AIChE Journal, Vol. 40, No. 4, pp. 627-644.

Tang, Y. T., Hung, S. B., Chen, Y. W., Huang, H. P., Lee, M. J., and Yu, C. C., 2005, "Design of Reactive Distillations for Acetic Acid Esterification with Different Alcohols," AIChE Journal, Vol. 51, No. 6, pp. 1683-1699.

Xu, Z. P., Afacan, A., and Chuang, K. T., 1999a, "Removal of Acetic Acid from Water by Catalytic Distillation. Part 1: Experimental Studies," The Canadian Journal of Chemical Engineering, Vol. 77, pp. 676-681.

Xu, Z. P., Afacan, A., and Chuang, K. T., 1999b, "Removal of Acetic Acid from Water by Catalytic Distillation. Part 2: Modeling and Simulation Studies," The Canadian Journal of Chemical Engineering, Vol. 77, 682-687.

Yu, C. C., 1999, Autotuning of PID Controllers, Springer-Verlag, London, UK.

Manuscript Received: Dec. 05, 2005 and Accepted: Dec. 06, 2005 


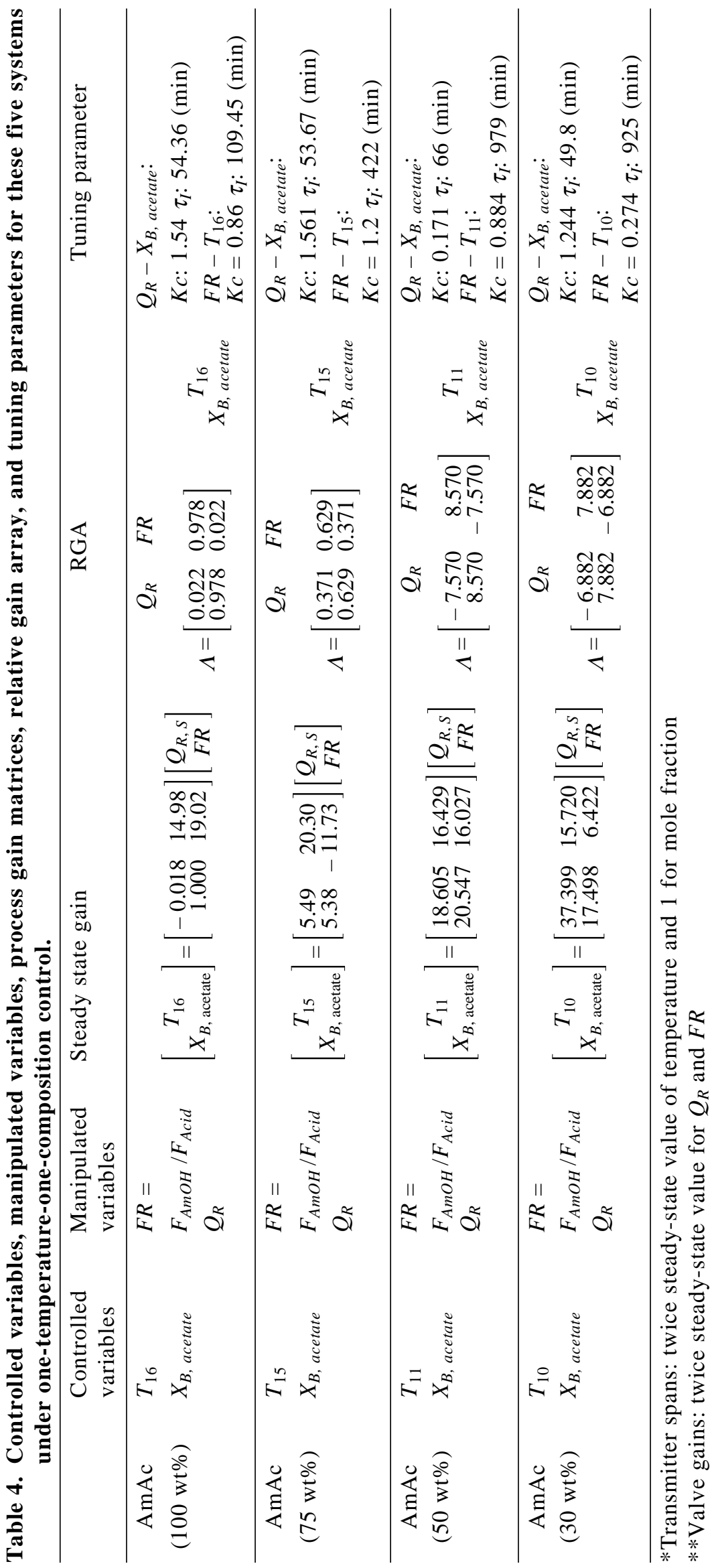



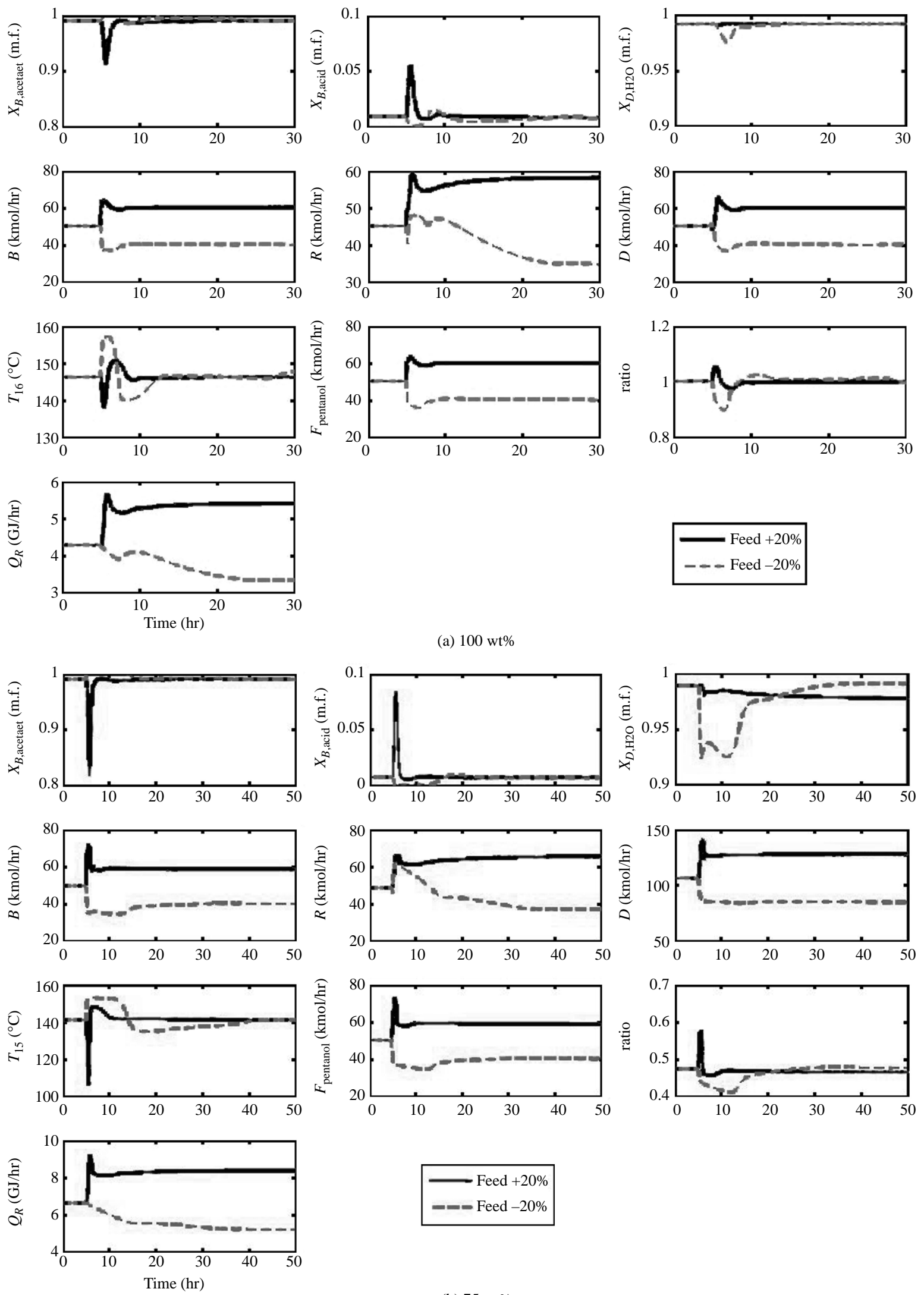

(b) $75 \mathrm{wt} \%$

Fig. 9 Composition control responses for $\pm 20 \%$ production rate changes for AmAc esterificaiton with different feed compositions of acetic acid 

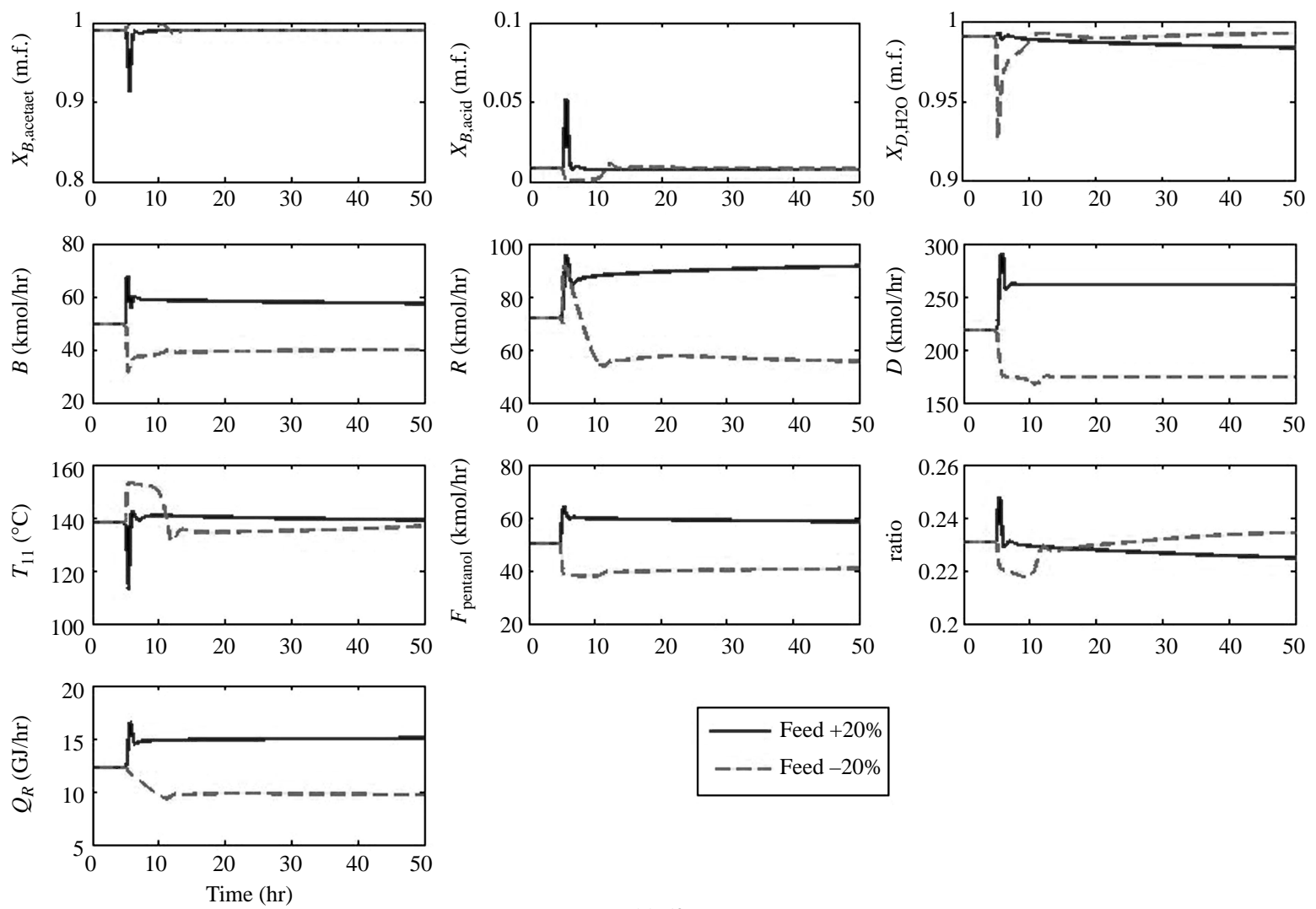

(c) $50 \mathrm{wt} \%$
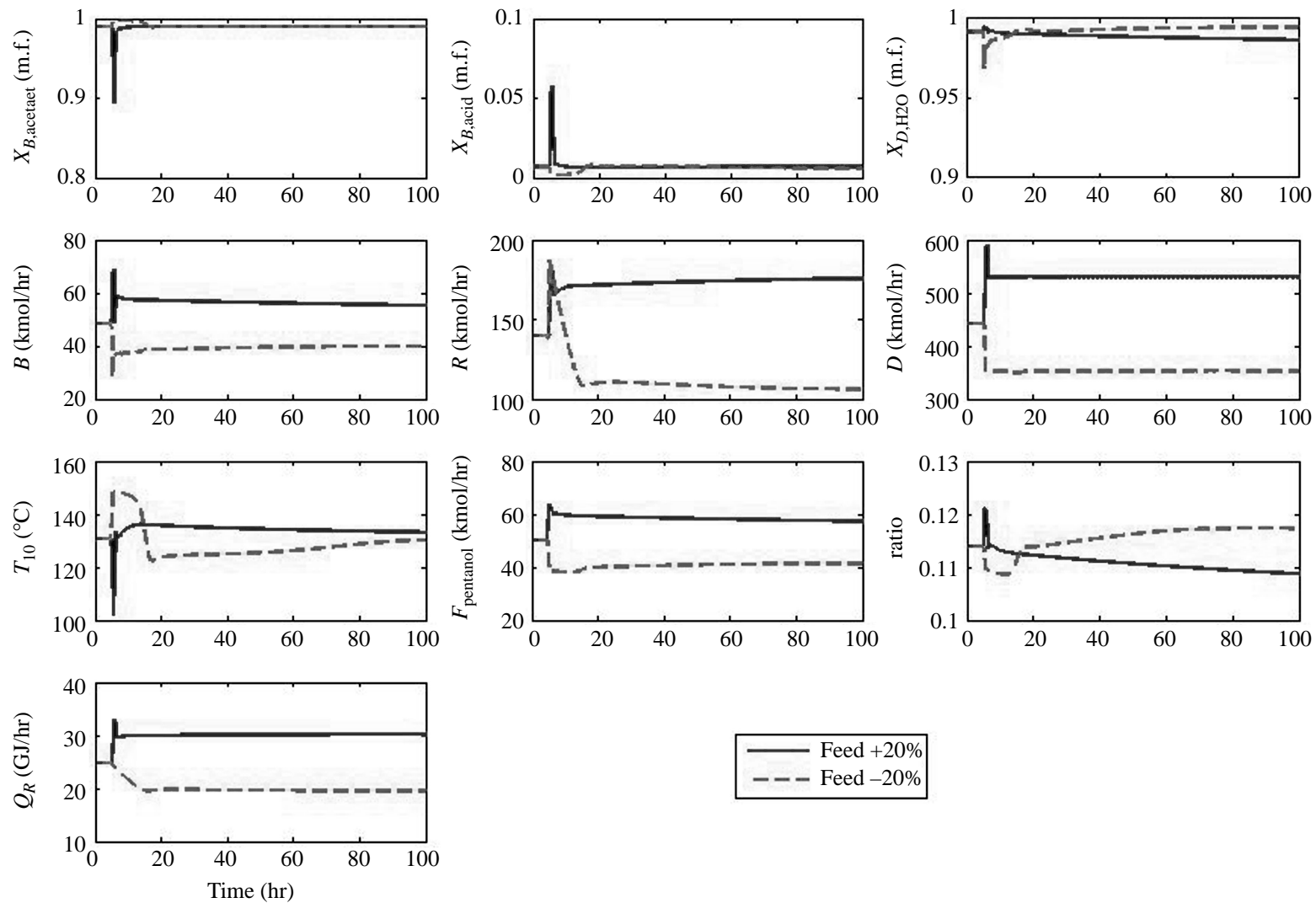

(d) $30 \mathrm{wt} \%$

Fig. 9 Composition control responses for $\pm 20 \%$ production rate changes for AmAc esterificaiton with different feed compositions of acetic acid (Continue) 